\title{
Student Perceptions of Self and Community within an Online Environment: The Use of VoiceThread to Foster Community
}

\author{
E. Gail Kirby ${ }^{1}$ and Nancy Hulan ${ }^{2}$ \\ Abstract: This paper investigates student responses to two tools used to \\ create learning environments that encourage the sharing of ideas and \\ discussion in online asynchronous university courses.
}

Keywords: asynchronous, VoiceThread, discussion board, participatory culture, student engagement, technology, New Literacies

The landscape of instruction has vastly changed teaching and learning in education during the last 10 years. With the emergence of technologies such as high speed Internet, virtual classrooms, blogs, wikis, and a plethora of other online tools, asynchronous online education has also become prevalent. A shift from face-to-face classes into the virtual world can seem a daunting challenge to many instructors and students. Some of us find ourselves trying the new bells and whistles, often unintentionally impeding instruction rather than reinforcing or furthering learning (Mandernach, 2006). Others search for ways to replicate the type of community and discussion that occur in face-to-face classrooms within the online environment. In this article, we describe our students' responses to the use of an asynchronous video sharing tool called VoiceThread in our quest to construct community within two university classes through the use of technology.

\section{Theoretical Perspective}

Drawing students into meaningful and engaging interactions and discussions in online settings can be difficult. This is a challenge because central to our understanding of how we learn is sociocultural theory, requiring that community and interaction play critical roles in learning (Vygotsky, 1978). We learn, process, are challenged, and have to rethink prior assumptions through interaction with others. It is our belief that such experiences can occur around the dinner table, on the playground, in the physical classroom, and when prepared and set up properly, in a virtual classroom. In fact, "both the process (the ways the instruction is delivered and the social interactions that contextualize the learning experience) and the content (the focus of instruction) are of major importance” (Snow, 2002, p. 16).

Rogoff (2003) studied learning within cultural contexts and the effects of culture on learning and teaching. A notable study she conducted involved children in African villages attempting to complete various tasks. These children were unsuccessful when they were given tools they were unfamiliar with-- when they were given tools with which they

\footnotetext{
${ }^{1}$ School of Teacher Education, Western Kentucky University, 1906 College Heights Blvd., Bowling Green, KY 42101, gail.kirby@wku.edu

2 School of Teacher Education, Western Kentucky University, 1906 College Heights Blvd., Bowling Green, KY 42101, nancy.hulan@wku.edu
} 
had experience, the children were successful in completing the task. Such also occurs with college students, many who feel comfortable within online environments and have “developed proficiency with gaming, social networking, video, and texting” (Leu, Forzani, Rhoads, Maykel, Kennedy, \& Timbrell, 2014a, p. 334). This does not mean that they effectively use online information, however.

Research has demonstrated that many students do not have critical evaluation skills when reading online and that they are not skilled in reading to locate information (Arend, 2009; Carmichael \& Farrell, 2012; Choy \& Cheah, 2009; Henderson-Hurley \& Hurley, 2013; Leu, Zawilinski, Forzani, \& Timbrell, 2014b; Rowles, Morgan, Burns, \& Merchant, 2013). The Internet "has brought unprecedented dimensions to both the speed and the scale of change in the technologies for literacy" (Coiro, Knobel, Lankshear, \& Leu, 2014, p. 2). In fact, researchers in the field of New Literacies suggest that literacy acquisition be defined not in terms of a static technology (e.g., print technology), but as "using a larger mindset and the ability to continuously adapt to the new literacies required" by new advances and technologies that quickly spread and become ubiquitous (2014, p. 5). We use Leu and colleagues' (2004) definition of New Literacies as enabling individuals to "use the Internet and other Information Communication Technologies (ICTs) to identify important questions, locate information, critically evaluate the usefulness of that information, synthesize information to answer those questions, and then communicate the answers to others” (p. 1570). For those who are not comfortable with technology, its ubiquity can be overwhelming. It is clear that technology will continue to become more prevalent in our lives, as reading shifts from page to screen (Carmichael \& Farrell, 2012; Leu et al., 2014a).

We examine the use of a specific online tool, VoiceThread, within an instructional context. This fits into Leu and colleagues' dual theory of New Literacies as an example of the lowercase perspective of new literacies. This examination is intended to determine the usefulness of one tool versus another. Such lowercase new literacy studies add to our more global understandings of uppercase New Literacies (Leu et al., 2014a; Leu et al., 2014b). One such understanding is that the Internet "makes new social practices possible” (2014a, p. 38); the use of VoiceThread for educational purposes and to foster community within an online environment fits within this understanding.

\section{The Landscape of Online Teaching}

Here we examine the world of online teaching in various groups, contexts, and subject matter to learn how it might benefit our own students.

\section{Participatory Culture}

In 2007, 1277 9-17 year olds spent their time online in various ways. They posted messages on message boards, shared music videos and photos, built sites, blogged, and created content (National School Board Association, 2007). These students are very creative with technology and use it in almost every facet of their lives. Yet, these are narrowed to social networking activities (Lenhart, 2015). Students are posting status reports about themselves and downloading photos and music, but they are not deliberately interacting with others. This showcases what they know best-themselves in the moment. Yet it does not encourage or involve the perspectives and experiences of others in their community. 
According to the National School Board Association (2007), only 10\% of tweens and teens participate in collaborative projects or send suggestions or ideas to websites. Fewer than $10 \%$ submit articles to websites or create polls, quizzes or surveys. While they are much more tech-savvy and prefer that the world around them offer access, they rarely participate in meaningful collaborative learning environments (Kelty, 2103; National Research Council, 2012; Turkle, 2011).

Such access to technology offers many opportunities and challenges to instructors involved in online teaching. There is unprecedented access to coursework due to the proliferation of high-speed Internet and online courses. In addition, due to the asynchronous nature of many online programs and courses, students have the option to complete class assignments at their convenience, in the comfort of their own home, and on their own schedules. As faculty in teacher preparation programs, we struggle to engage students through technology to learn in online environments. As previously stated, fortyone percent of students post personal messages (National School Board Association, 2007). They post their experience but don't interact with other students' contributions. This is important because learning stops at the student who does not engage with others (Pellegrino \& Hilton 2012).

Learning is a socially mediated process (Vygotsky, 1978; Feuerstein, Feuerstein, \& Falik, 2010), requiring that we take part in meaningful interactions with peers and pertinent content. Thus, the challenge we confront in this article is finding a way to build community and discussion in online coursework. Early work by Keller (1983) suggests that student curiosity through manipulation and exploration might sustain and increase learning when students are in charge of their learning environment. In asynchronous coursework, often students are asked to respond to one another's written contributions via Discussion Board. We contrast the traditional online discussion board with VoiceThread to examine students' preference of one tool versus another and ways the use of oral communication rather than written may boost a sense of community.

\section{Discussion Boards}

Most college students who have taken online courses have some experience with Discussion Boards. Discussion boards typically require students to respond to a prompt from a teacher or text and students are usually able to see all of their peers' written responses. Students feel comfortable with discussion boards, as the technology is not very challenging. However, discussion boards pose a few challenges to faculty. The set-up of discussion boards tends to cause students to reiterate what a previous post may have said, and limits students' need to go further, dig deeper, or challenge one's self or their peers. Many students admit to copying portions of their peers' posts and simply adding a few examples to make the submission their own. Other students feel comfortable with discussion boards because they are seen as "fluff" in a class-not seen as a tool for furthering understanding. In addition, many faculty find discussion boards to be excruciatingly boring to grade (because most students simply restate what previous students have written), and responses lack personality. It is impossible to really get to know someone through a written discussion board, so that sense of the face-to-face community is absent within the class that only uses such a tool. 


\section{VoiceThread}

Brunyard and Byrd (2011) define VoiceThread as an "interactive, multimedia slideshow tool," which allows users to hold discussions around "images, documents, and video. This tool is easily accessible, cost-effective, applicable across most subject matter and grade levels, and adaptable to many learning settings” (p. 28). In addition, VoiceThread allows the users to choose their form of participation. One can choose to post an image or a video, type a response through speech bubbles or in a PowerPoint slide, use their phone to receive a call from VoiceThread, which allows them to speak their response, or a combination of the above. This ability to choose can increase intrinsic motivation (Keller, 1983; Malone \& Lepper, 1983). VoiceThread has also been shown to be a useful tool to differentiate instruction for struggling students due to the expanded options for demonstrating understanding (Brunyard \& Byrd, 2011). These options promote engaged collaboration that strengthens student participation in their learning environment. One of the features of VoiceThread for students with disabilities is the inherency of wait time, which allows students valuable time to form responses, often not available in the face-to-face pace of the classroom.

\section{Methods}

Through this research, we seek to answer the following questions:

What differences and similarities exist between graduate and undergraduate students' views of themselves as contributors to the online classroom environment via VoiceThread versus Discussion Board?

How does a technology such as VoiceThread create a sense of community in online discussion?

\section{Population}

Two classes in a School of Teacher Education at a university in the south were used in this study. One group consisted of 23 undergraduate students taking a Language Intervention Strategy class. Their class met regularly in person and used VoiceThread as a supplemental tool to foster community among students and discussion about theory. This group used VoiceThread three times to answer prompts from the instructor based upon readings, class activities, and classroom observations.

The other group was composed of 16 graduate students taking a Literacy Theory course, which was offered completely online and used VoiceThread 12 times during the semester as a way to foster community and discussion. The first VoiceThread was an introductory exercise in which students created videos to introduce themselves to their classmates. Students responded to at least three peers' entries. All other assignments involving this technology required the student to read articles dealing with literacy theory and to respond to one of a variety of questions specific to the readings.

\section{Instrument}


A questionnaire was created for administration to students in each of these courses. Questions were developed to glean information from students regarding their use of discussion boards versus VoiceThread. The questionnaire is included in Appendix A. Students were given online access to this questionnaire upon completion of the courses.

Data Analysis

Questionnaire results from undergraduate and graduate students were analyzed using the Constant Comparative Method of Qualitative Analysis (Glaser \& Strauss, 1967). The authors read all student responses, identified and discussed themes, and then coded one set of responses separately to determine their interrater reliability of $89 \%$. All responses were coded and codes were discussed among the authors to insure consensus and to refine codes and themes, as needed.

\section{Results}

Students answered questions related to their use of VoiceThread and Discussion Board in undergraduate and graduate course work. Here we describe students' reactions to each of the questions asked.

What do you like about using VoiceThread for class assignments?

Students' answers fell into the following themes: interactive, depth, intimacy, ease, and access. Examples of student responses that were coded with each of these themes are shared in the following table:

\section{Table 1. VoiceThread themes}

\begin{tabular}{|c|c|}
\hline Theme & Examples \\
\hline Interactive & $\begin{array}{l}\text { - The video makes it feel more interactive. Hearing the voice of a } \\
\text { classmate brings about feelings that a class discussion is taking } \\
\text { place rather than reading something you have read from a } \\
\text { faceless peer. } \\
\text { - It makes discussion more interactive and expressive. }\end{array}$ \\
\hline Depth & $\begin{array}{l}\text { - I liked it because it seemed people could go more in depth and get } \\
\text { out what they really wanted to say. } \\
\text { - They helped me follow along and learn better. } \\
\text { - I believe VT encourages a greater depth of understanding of not } \\
\text { just the material relevant to the question being answered, but to } \\
\text { the material in general. } \\
\text { - You get to thoroughly plan out your responses prior to giving } \\
\text { them. }\end{array}$ \\
\hline Intimacy & $\begin{array}{l}\text { - It creates a higher level of intimacy. } \\
\text { - It is nice to be able to see my classmates and hear their voices } \\
\text { since we don’t meet in person. }\end{array}$ \\
\hline
\end{tabular}

Journal of Teaching and Learning with Technology, Vol. 5, No. 1, July 2016

jotlt.indiana.edu 


\begin{tabular}{|c|c|}
\hline & $\begin{array}{l}\text { - It makes it (class) a little more personal. } \\
\text { I liked hearing people's thoughts better than reading them } \\
\text { because it was easier to tell how the person felt when I could hear } \\
\text { the tone of their voice. }\end{array}$ \\
\hline Ease & $\begin{array}{l}\text { - It saves time on typing and is easy to use. } \\
\text { - It is easy to use and navigate through. } \\
\text { - I like being able to communicate my ideas verbally as well as } \\
\text { visually. } \\
\text { - It is easier to listen to a lengthy discussion than to read a lengthy } \\
\text { narrative. }\end{array}$ \\
\hline Access & $\begin{array}{l}\text { - It gives people who normally wouldn't talk a chance to give their } \\
\text { opinion. } \\
\text { - It is helpful for the student to be able to express him/herself. }\end{array}$ \\
\hline
\end{tabular}

In comparing graduate students' responses with undergraduate students' responses, they showed differences in feelings toward the tool. Graduate students responded with the following themes from most to least frequency: Intimacy, depth and ease, interactive, and access. Undergraduate students responded with the following themes from most to least frequency: Ease, intimacy, depth and access, and interactive. Slight differences indicate that the graduate students were more interested in the intimacy and depth that the tool provided than the undergraduate students who were more interested in the ease of the tool and then the intimacy it afforded.

What were your challenges in using VoiceThread for class assignments?

Students' answers to this question reflected a paradigm shift from the technology they were accustomed to (Discussion Boards) toward the new technology of VoiceThread. These shifts were evident in the fear of new technology, in their need to pay attention to the clarity of their speech to engage the listener, and a shift in time management, as VoiceThread was said to take more time to create than the more familiar Discussion Board.

What do you like about using Discussion Board for class assignments?

Students in graduate and undergraduate courses responded similarly to this question. Themes included: depth, ease, communication, and focus on self. The majority of all students said that they liked the ease of use and of the assignments on Discussion Board. Of statements coded for these themes, the following table shows student response rates and example statements.

Table 2. Student response rates and example statements

\begin{tabular}{|l|l|l|l|}
\hline Theme & $\begin{array}{l}\text { Undergraduate } \\
\text { number of } \\
\text { statements }\end{array}$ & $\begin{array}{l}\text { Graduate } \\
\text { number of } \\
\text { statements }\end{array}$ & Example statements \\
\hline
\end{tabular}

Journal of Teaching and Learning with Technology, Vol. 5, No. 1, July 2016

jotlt.indiana.edu 


\begin{tabular}{|c|c|c|c|}
\hline Ease & 9 & 13 & $\begin{array}{l}\text { - I like it because it is all on the } \\
\text { Blackboard site. Everything } \\
\text { is there together. } \\
\text { - I like using discussion boards } \\
\text { for class assignments because } \\
\text { they are easy to use. }\end{array}$ \\
\hline Depth & 5 & 3 & $\begin{array}{l}\text { - They encourage me to think } \\
\text { in greater depth and respond } \\
\text { with clarity. } \\
\text { - When completing discussion } \\
\text { boards I feel more free to } \\
\text { openly discuss ideas and } \\
\text { thought with classmates and } \\
\text { professors because they do } \\
\text { not hold as much pressure as } \\
\text { other assignments. }\end{array}$ \\
\hline Communication & 5 & 3 & $\begin{array}{l}\text { It was a way for us as a class } \\
\text { to share our thoughts and } \\
\text { feelings about topics and a } \\
\text { way to communicate. }\end{array}$ \\
\hline Self-focus & 3 & 0 & $\begin{array}{l}\text { I like following what people } \\
\text { have said about what I } \\
\text { wrote. I can easily skip to } \\
\text { posts by people who I think } \\
\text { usually have something worth } \\
\text { reading. } \\
\text { - I like being able to give my } \\
\text { opinion and read the } \\
\text { responses to my posts. }\end{array}$ \\
\hline
\end{tabular}

What are the challenges to using Discussion Board for class assignments?

Graduate and undergraduate students overwhelmingly responded that there are no challenges in the creation of assignments using Discussion Board. However, many students did note that postings on Discussion Boards are often repetitive and redundant, and that it is very time consuming to read everyone's posts. The majority of the responses pointed to the notion that the written word in today's digital world is simply limited. It can be difficult for students to understand what their classmates are trying to say if their posts are not wellwritten and missing the inflection of a person's voice or the look on their face. Nonverbal cues are missed in responses that are written in Discussion Boards.

What mode of communication requires more preparations and effort? 
Almost unanimously, students responded that VoiceThread required more preparation and effort. They described the need to write out their answer in an outline or script, rehearsing their responses, and then ultimately recording it. Students reported that for Discussion Boards they simply typed their answer and were done with it.

How was your preparation for creating VoiceThreads different from your preparation for creating Discussion Boards?

Students were split on this question, but overall felt that preparation for submitting a response on VoiceThread was more intensive. This was attributed to a need for learning new equipment, to write a script and then practice saying/reading the script several times before recording, and a general requirement to spend more time on their responses and assignments. While a Discussion Board typically only required typing an answer, a VoiceThread response often required many more steps.

One striking difference involved students' need to seem prepared and knowledgeable in their VoiceThreads that was not evident in the preparation for Discussion Boards. One student stated, "I prepare what I am going to say first and type it into a word document. Then I create a PowerPoint for my presentation and upload it to VoiceThread. Once I have done all of that, I record my voice for the presentation.” In contrast, this same student stated, "For Discussion Board, I prepare a word document for my response and then I post it to the Discussion Board." Another student stated, "You can't fake your way through it (VoiceThread)," insinuating that you can, in fact, fake your way through a Discussion Board.

While this question asked students to think about preparation, many wrote about their level of understanding resulting from the different types of assignments. For instance, several students stated that they learned more through the preparation of VoiceThreads than through the preparation of Discussion Boards, "Preparation is more in-depth, and is more focused on delivery as well as content, as both affect each other. I think a greater depth of understanding of the material is necessary, and sometimes it is necessary to project self into the picture, asking one's self if the content inspires reflection by the reader."

In contrasting undergraduate responses to graduate responses, it was clear that graduates were more focused on meaningful results from assignments than the undergraduates, who focused more on the equipment and the time spent than the meaning they reaped from experiences.

In which format are you more inclined to participate beyond the required amount?

In response to this question, graduate and undergraduate students were very different. The majority of graduate students (13 out of 17) responded that they were more inclined to participate beyond the required amount using VoiceThread. Reasons for this included "VoiceThread resembles the classroom setting more," "People just use Discussion Boards for 'fluff' and don't really try to interact," and "I am more inclined to participate in the VoiceThread because I feel I have learned more that way."

In contrast, undergraduate students were split on this question. Of 22 responses, 10 preferred VoiceThread, 9 preferred Discussion Board, and one student didn't have a 
preference. Reasons varied, but the majority of respondents chose Discussion Board because they were comfortable with it and it took less time, and those who chose VoiceThread did not share reasons. One student had a mixed response, "I prepare a better initial answer for VoiceThread but post more responses and look at the posts of my peers more on Discussion Boards.”

How would you like instructors to use Discussion Board/VoiceThread in future classes?

Due to the logistical differences between groups (synchronous vs. asynchronous), undergraduates suggested a few ways that faculty might use VoiceThread: as a "check for understanding" discussion feedback type of exercise following what was covered in class, as a way to voice opinions, receive constructive feedback, or as an explanation of upcoming assignments that students could go back to view as a reference. Some suggestions were more vague, such as "mix them up." One student reported that VoiceThread "was just a more complicated Discussion Board."

The graduate students were more creative with their suggestions: VoiceThread could be used on group projects, peer assessments, collaborative scoring, presentations of learning, open forums for questions, and Blogs. One student wanted a discussion board set up 'where students could talk about issues they were having with the class or a specific concept" so they could help each other. Some responses were ambivalent, but many of those included the observation that VoiceThread became easier once practiced. Above all, one student summarized that "If discussion board or VoiceThread is going to be used, it should be something useful and not just busy work."

Do you feel VoiceThread increased your engagement and interest in the course content?

An overwhelming response from graduate students to this question was that VoiceThread did increase engagement, but not interest, in the course content. Truly, an online tool meant to foster discussion and community is not expected to increase interest, but rather a sense of community that would help to promote engagement. Thus, the reaction from students makes sense. Of undergraduates, again the group was split between whether VoiceThread increased engagement or not. Eleven undergraduate students agreed that VoiceThread fostered engagement but not interest. Seven students did not think that VoiceThread increased interest or engagement.

Does VoiceThread make your class experience feel more personal than a Discussion Board?

Students responded to this question by addressing the tool's ability to make the course seem more interactive, to add to the depth of answers-in that students were more likely to open up about their answers, to add to the sense of relationship within the class, and to help students to understand the clarity of a student's intention (based on tone). Graduate students felt that VoiceThread did make the class experience feel more personal; undergraduate students were split due to the limited number of experiences they had with the tool and the fact that they already held class face to face. Students made statements 
such as, "The assignments allow us to get to know each other better." One student did not like the fact that VoiceThread made the experience more personal.

\section{Discussion}

Analysis of these results yields some interesting conclusions. We find that there are, in fact, differences between the undergraduate and graduate students' views of themselves as contributors to the online classroom environment. Graduate students were more focused on the depth and content of their contributions than the undergraduates, who were more focused on the ease or difficulty of using the tool. Undergraduates tended to be more passive learners, while graduate students seemed to have more agency, and were more active learners.

In addition, graduate students were much more focused on their classmates than the undergraduates. Graduates wanted to craft their contributions to be engaging and thought provoking for the other students. Few undergraduate students mentioned the impact their contributions might have on their peers. For undergraduates, the patterns described from 2007 still prevail. The generation of our undergraduates is used to ubiquitous access and a focus on themselves in the media. They can create content via blogs, wikis, YouTube, snapchat, etc. However, this focus on self-created content also leads these same students to a self-focus in the classroom, rather than the stance of critically analyzing the thoughts and contributions of others. Their focus is more on themselves rather than on collaboration or community, even in the online environment.

Finally, there was more of a focus on preparation for VoiceThreads among all students than for Discussion Boards. These took extra steps and often rehearsal, while the Discussion Boards required less time and effort. This extra emphasis on preparation led several students to admit that they learned more from VoiceThread assignments than from Discussion Boards.

We found that the use of VoiceThread created an increased sense of community while Discussion Board did not. This was evident in students' responses. They felt that hearing their peers' voices, seeing their faces, and sometimes seeing their surroundings helped them to get to know their classmates. The nature of speaking rather than writing also led to this conclusion, as several students commented that being able to hear inflection and tone aided in understanding students' responses and thus, their fellow students as individuals. This sense of community through the use of VoiceThread was stronger in the online graduate course than in the face-to-face undergraduate course, probably due to the fact that the online class only had VoiceThread to aid them. The use of VoiceThread did not enhance a sense of community in the face-to-face class, as they were able to create that in the classroom. In addition, the online course used the tool 12 times while the face-toface class only used it three times. Perhaps it is necessary to build a familiarity with any tool used to foster discussion before it can promote a sense of community.

Based on the findings of this study, the use of VoiceThread in online coursework did, in fact, further learning and did not, as Mandernach (2006) warns, impede instruction. The tool did foster a sense of community in the online graduate course in which students used the tool many times and where it served as the main tool for interaction between classmates. It did not boost a sense of community in the undergraduate class that met in person for three possible reasons: 1) students had opportunities to build community in other 
ways, 2) students used the tool a limited number of times, limiting its effectiveness, or 3) undergraduate students may not react to such tools in a learning environment in the same way as graduate students.

\section{Implications}

This research adds to the current knowledge base regarding online engagement and community building. The use of VoiceThread enhances students' sense of rigor and community because it enables them to choose the mode of delivery and allows them to see and hear their classmates. Since this study was conducted, other tools have been created that can add to online teachers' toolboxes for infusing rigor and community into the online classroom. Such tools include a video sharing feature that has been added to Discussion Boards, Zoom.us, WebEx.com, and Gotomeeting.com.

One additional challenge to the online educator is the need to stay current with evolving technology. Such technological advances should be treated as tools to engage, create a sense of community, and increase rigor in the classroom. Online educators should ask, "Why do I want to use this technology?" "What will it add to my students' experience in this online course?"

"It could well be that faculty members of the twenty-first century college or university will find it necessary to set aside their roles as teachers and instead become designers of learning experiences, process, and environments” (Duderstadt, 1999, p. 7). As New Literacies make new social practices possible (Leu, et al., 2014a), educators have the opportunity to selectively use new literacies tools to promote learning, engagement, and community. This study demonstrated how the use of one such tool, VoiceThread, can boost a sense of community within the online classroom environment.

Future research should continue to investigate the nuances of using such tools with students in different contexts.

\section{Appendix A. Questionnaire}

\section{Appendix}

1. What do you like about using VT for class assignments?

2. What were your challenges in using VT for class assignments?

3. What do you like about using Discussion Board for assignments?

4. What are your challenges in using Discussion Board for class assignments?

5. What mode of communication requires more preparations and effort?

6. How was your preparation for creating VoiceThreads different from your preparation for creating Discussion Boards?

7. In which format are you more inclined to participate beyond the required amount?

8. How would you like instructors to use Discussion Board/VoiceThread in future classes?

9. Do you feel the VoiceThread increased your engagement and interest in the course content?

10. Does VoiceThread make your class experience feel more personal than a Discussion Board? 


\section{References}

Brunyard, S., \& Byrd, S. (2011, March/April). Using VoiceThread to promote learning engagement and success for all students. Council for Exceptional Children, 28-37.

Duderstadt, J. J. (1999). Can colleges and universities survive in the information age? In Katz, R. N. \& Associates (Eds.). Dancing with the devil: Information technology and the new competition in higher education (1 -25). San Francisco, CA: Jossey-Bass.

Feuerstein, R., Feuerstein, R. S., \& Falik, L. H. (2010). Beyond smarter: Mediated learning and the brain's capacity for change. New York, NY: Teachers College Press.

Glaser, B. G., \& Strauss, A. L. (1967). The discovery of grounded theory: Strategies for qualitative research. New York, NY: Aldine DeGruyter.

Henderson-Hurley, M., \& Hurley, D. (2013). Enhancing critical thinking skills among authoritarian students. International Journal of Teaching and Learning in Higher Education, 25 (2), 248-261. doi: 10.1080/10511250300085841

Keller, J. M. (1983). Motivational design of instruction. In C. M. Reigeluth (Ed.). Instructional design theories and models: An overview of their current status, 383-434. Hillsdale, NJ: Erlbaum.

Kelty, C. M. (2013). From participation to power. In Delwiche, A., \& Henderson, J. J. (Eds.), The Participatory Cultures Handbook, 22-32. New York, NY: Routledge.

Lenhart, A., (August 6, 2015). Teens, Technology and Friendships. Pew Research Center's Internet \& American Life Project. Retrieved from http://www.pewinternet.org/2015/08/06/teens-technology-and-friendships/

Leu, D., Forzani, E., Rhoads, C., Maykel, C., Kennedy, C., \& Timbrell, N. (2014a). The New Literacies of online research and comprehension: Rethinking the reading achievement gap. Reading Research Quarterly, 50 (1), 37-59.

Leu, D. J., Zawilinski, L., Forzani, E., \& Timbrell, N. (2014b). Best practices in new literacies and the new literacies of online research and comprehension. In Morrow, L. M. \& Gambrell, L. B. (Eds.) Best practices in literacy instruction (5th ed.). New York, NY: Guilford Press.

Mandernach, B. J., \& Taylor, S. S. (2011). Web 2.0 Applications to foster student engagement. In R. L. Miller, E. Amsel, B. M. Kowalewski, B. C. Beins, K. D. Keith, \& B. F. Peden (Eds.). Promoting student engagement, Vol. 1: Programs, techniques, and opportunities, 220-229. Society for the Teaching of Psychology, APA.

Mishra, P., \& Koehler, M. J. (2006). Technological pedagogical content knowledge: A framework for teacher knowledge. Teachers College Record, 108 (6), 1017-1054.

Malone, M. R., \& Lepper, M. R. (1983). Making learning fun. In R. E. Snow \& J. F. Marshall (Eds.), Aptitude, learning, and instruction: Cognitive and affective process analyses, 3, 223-253. Hillsdale, NJ: Lawrence Erlbaum Associates.

National Research Council. (2012). Education for life and work: Developing transferable knowledge and skills in the 21st century. Washington, D.C. Retrieved from http://sites.nationalacademies.org/dbasse/bota/index.htm

National School Board Association. (2007). Creating and connecting: Research and guidelines on online social and educational networking. Grunwald Associates, LLC.

Pellegrino, J. W., \& Hilton, M. L. (Eds.). (2012). Education for life and work: Developing transferable knowledge and skills in the 21st century. Washington, DC: National Academies Press. 


\section{Kirby and Hulan}

Rogoff, B. (2003). The cultural nature of human development. Oxford: Oxford University Press.

Snow, C. E. (2002). Reading for understanding: Toward a research and development program in reading comprehension. Santa Monica, CA: RAND.

Turkle, S. (2011). Alone together: Why we expect more from technology and less from each other first. New York, NY: Basic Books. 